\title{
Beyond the language barrier
}

Sir - I disagree with the contention of Paul R. Sanberg and his colleagues in recent correspondence ${ }^{1}$ that "regional and local foreign institutions should continue Japan's approach of providing important Englishlanguage journals". It is a bad excuse indeed to claim that "important discoveries" are only "rediscovered" a few years later in another country simply because of a so-called "language barrier". The continued ignorance of scientific publication often has more to do with the attitudes of scientists and of abstracting/indexing service providers.

For example, the Institute of Scientific Information (ISI) covers only a small fraction of archaeological periodicals published in Britain and Ireland for its Arts and Humanities Citation Index, yet the many journals that are not covered contain predominantly English-language papers, including important reports on archaeological excavations and surveys ${ }^{2}$. If a 'language barrier' is not the problem, then what can it be?

Perhaps intellectual imperialism is at work here. Ireland has many local and society journals, yet only four Irish periodicals are covered by ISI for its Arts and Humanities Citation Index ${ }^{3}$. Other bibliographical and abstracting services such as the on-line Celtic Studies Bibliography of the Celtic Studies Association of North America $^{4}$, the International Medieval Bibliography, the British Archaeological Bibliography and the Royal Historical Society's Annual Bibliography of British and Irish History all include Irish archaeological periodicals not covered by ISI. However, none of these bibliographies is as comprehensive as it ought to be. This is due to funding cutbacks that make it difficult for academic libraries to subscribe to a wide range of foreign and indigenous periodicals, and this has had a knock-on effect to bibliographers who use these libraries for their compilations. In the recession of the 1990s, subscriptions to bibliographies have also fallen, as in the case of the British Archaeological Bibliography, giving rise to concern that (in this instance) archaeologists in Britain and Ireland will not be able to keep up to date in their profession ${ }^{5,6}$.

Although increased funding for libraries and abstracting/indexing services should augment scholars' knowledge of published work in other countries, the view that publication ought to be only in English is a bad one. At a time when science is increasingly being criticized for all kinds of reasons, the promulgation of such a view only lends support to its detractors. Not only could the charge of academic imperialism be laid against the principle of a monoglot publication practice but it would also mean that fewer members of the wider public in non-English-speaking countries would be able to read the reports published by their own scientists. This would inevitably lead to a decline in the political clout of scientists within these countries, because their work might come to be seen as irrelevant to the concerns of their respective nations. Furthermore, adopting a single language for scientific communication would reverse the progress in democracy gained when Westerners moved away from the patrician use of Latin for all academic, legal and religious endeavour towards a more inclusive use of vernacular languages instead.

\section{G. Fewer}

Les Revenants,

Corballymore,

Dunmore East,

Co. Waterford, Ireland

e-mail:gfewer@staffmail.rtc-waterford.ie

Sir - As Sanberg et al. ${ }^{1}$ point out, there is no doubt that the presence in Japan of Englishlanguage journals in science shows that Japanese scientists have become international in their outlook. But this does not show the whole picture. In my opinion, there are two mundane reasons for the existence of English-language journals in Japan.

First, the medical journals published by many of the 80 or so medical schools in Japan provide an easy route for faculty members in these institutions to accumulate publications in English without proper - or even any - peer review. Papers in these obscure journals may be accepted on the whim of an over-burdened editor lacking the expertise needed to assess the quality of submitted manuscripts.

Second, these medical journals also serve as a cash-cow to the 'English industry' in Japan. The majority of Japanese scientists (medical doctors included) offer good money for their manuscripts to be rewritten and edited. A few years ago, I received an invoice for nearly US $\$ 500$ for "improving the English" of a manuscript submitted to a local journal published by a reputable medical school. I had previously had manuscripts accepted by journals in the United States and Britain (including Nature) without any request for changes to the English.

\section{Sachi Sri Kantha}

5-16-305 Tsukimicho,

Fukuroi City,

Shizuoka pref. 437-01, Japan

Sir - I have been among the authors of about 30 research papers in international journals published in Europe and the
United States, and have thus had the opportunity of seeing reviews from many referees. The research was essentially experimental and was conducted within the framework of accepted ideas and experimental techniques. From my own experience I have regretfully to agree with Franklin D. Rumjanek ${ }^{7}$.

When a research paper by unknown authors from an unknown university in a developing country such as India is presented to an international journal, it may be natural for a referee working in a highly evolved research culture in a developed country to be sceptical about the quality of the work. Such a sceptical attitude was evident in some (but not all) of the reports I and my colleagues received. This taught us to aim for a higher standard than the average for papers published in such journals and to accept with stoic equanimity what may have been unfair rejection of a paper.

I should add that the prejudices of some scientists in developed countries against the work of their economically poor peers is insignificant compared to the prejudice based on religion, region, mother tongue and caste that I see in my own country.

N. Umakantha

19 R.K. Nagar,

Dharwad 580 003, India

Sir - I work in the translation service of a German research centre, and from time to time authors show me papers that have been returned by English-language journals with comments to the effect that the language is "poor" or "needs revision".

Some of the papers have already passed through our hands, and in my opinion the English is unobjectionable. Such comments are particularly maddening if no errors are indicated on the manuscript, just a blanket condemnation.

Like Rumjanek $^{7}$, I put this down to prejudice against foreign, or rather nonanglophone, authors. We now resubmit the same paper, with minor cosmetic revision, adding that it has been revised by a member of staff from the language service. This policy has so far met with resounding success.

\section{Janet Carter-Sigglow}

Am Vogeldriesch 1B,

52441 Linnich, Germany

1. Sanberg, P. R., Borlongan, C. V. \& Nishino, H. Nature 384, 608 (1996).

2. Fewer, G. Trial Trench 4, 2-3 (1995).

3. http://www.infohwy.com/ gfewer/cithum.htm

4. http://www.humnet.ucla.edu/humnet/celtic/wwwbib995.html

5. Heyworth, M. Br. Archaeol. 8, 10 (1995).

6. Lavell, C. \& Haydock, I. Br. Archaeol. 10, 10 (1995).

7. Rumjanek, F. D. Nature 384, 509 (1996). 